\title{
Discurso em homenagem ao Supremo Tribunal Federal.
}

\author{
Celso Neves \\ Professor Titular de Direito Processual Civil \\ na Faculdade de Direito da Universidade de \\ São Paulo
}

Núncio de uma Congregação que, como expressão maior da minha vida de professor, tenho a honra insigne de integrar, cuidarei de não desmerecê-la, neste momento, não somente pela nobreza da missão recebida, como pela validade de seu significado, no mundo emocional em que se insere o pretexto altíssimo desta comemoração. Cuida-se de festejar o egrégio Supremo Tribunal Federal, no ano em que completa século e meio de uma fecunda existência, no sítio em que - já lá se vão, também, mais de cento e cinqüenta anos - demora o Capítulo a que pertencemos, aqui reunido, nesta noite, no velho convento que o viu nascer e florescer, para um ato de recolhimento com que damos graças pelo fato e pelas circunstâncias do fato que nos leva a esta vigília de testemunho e sagração.

Somos "uma escola que se pode dizer fruto de nossa independência e tem quase o mesmo tempo da nossa liberdade. Uma escola que cultiva esses predicados que a viram nascer e vive sob esse mote, tabernáculo das nossas mais caras tradições de cultura e civismo e batistério pelo qual passaram os maiores vultos da nossa história. Os que aqui habitam são tocados pela magia da saga de que se faz o espírito que a tem vivificado, durante mais de trinta lustros de sobranceira existência, patrizando-se com as galas dos heróis que os precederam", na aura de paladinos dos mesmos ideais. E, por isso mesmo, importa que aqui se cultuem nossas instituições maiores, que se revestem das mesmas púrpuras e vivem o mesmo destino, na obra sagrada de edificação deste país.

\footnotetext{
* Discurso proferido na sessão solene da Congregação, realizada no dia 4 de dezembro de 1978, às 20,30 horas, em homenagem ao Supremo Tribunal Federal, pelo sesquicentenário de sua criação.
} 
Não será demais repetir que a realização da Justiça, na estrutura administrativa do Brasil dos tempos coloniais foi das mais precárias. Nem é estranho que assim tenha sido, se medirmos os problemas da própria colonização, agravados pelos episódios que assinalaram o transcorrer dos séculos XVII e XVIII, num período histórico em que ideais e preconceitos iriam interferir na própria concepção dos rumos a serem traçados, sem plena consciência de que se armava, nas terras conquistadas, o futuro de contrastes e confrontos que agora vivemos.

No período das Capitanias, o Ouvidor, nomeado pelos donatários, exercia, no cível e no crime, toda a jurisdição. Estabelecido o governo unitário, em meados do século XVI, aqui se instalou o Ouvidor Geral, com funções semelhantes a dos ouvidores de até então.

A 7 de março de 1609, cria-se a Relação da Bahia tribunal de solenidade e aparato, na opinião de historiador ilustre, com o qual se pretendia melhorar a administração superior da Justiça - que, dizia D. FELIPE, ao ordená-la:

"parece que hoje he mais importante e necessario, per razão do descobrimento e conquista de novas terras e augmento do commercio, com que se tem dilatado muito aquelle Estado, assim em numero de Vassallos, como em grande quantidade de fazendas, por cujo respeito crescerão as dúvidas e demandas, que cada dia se movem".

Tal a Relação que, menos de vinte anos depois, por Alvará de 5 de abril de 1626, por não haver atendido aos intentos da Corôa, veio a ser extinta, passando a administração da Justiça aos Ouvidores Gerais que, desde 1.619, eram três: o da Bahia, mais os do Rio de Janeiro e do Maranhão que nesse ano foram criados.

Já no Reinado de D. João IV, por lei de 12 de setembro de 1652, foi restabelecida, na Bahia, a Relação do Brasil, só instalada a 3 de março de 1653. Para isso influíram, não só os reclamos do povo como as instâncias da Câmara local e do Governador, Rodrigues de Vasconcelos. Durante quase um século, essa foi a cúpula da administração da Justiça em nosso país, pois somente a 13 de outubro de 1751, já no reinado de $D$. José $I$, veio a ser criada a Relação do Rio de Janeiro, com jurisdição sobre territórios do Sul que compreendiam, também, as comarcas de Campos dos Goitacazes, Espírito Santo, São Paulo, Ouro Preto, Rio das Mortes, 
Sabará, Rio das Velhas, Serro Frio, Cuiabá, Goiases, Paranaguá, Ilha de Santa Catarina e as judicaturas, ouvidorias e capitanias que, no mesmo distrito da Relação, se viessem a instalar.

Com jurisdição restrita às capitanias da Bahia, Sergipe, Pernambuco, Rio Grande do Norte, Paraíba, Ceará, Piauí, Maranhão, Pará e Rio Negro - de Porto Seguro, portanto, até esta última - perdeu a Relação da Bahia a denominação de Relação do Brasil que, enquanto única, manteve.

Em 1812, após a vinda da família real para o Brasil, cria-se a Relação do Maranhão - com jurisdição sobre as comarcas do Ceará, Piauí, Maranhão, Pará e Rio Negro e, em 1821, a Relação de Pernambuco, com jurisdição sobre áreas retiradas da Relação da Bahia e do Maranhão, abrangentes das comarcas do Recife, de Olinda, do Sertão, da Paraíba, do Rio Grande e do Ceará.

Até 1808, sobre as Relações existentes pairavam os juízes da Casa de Suplicação de Lisboa, criada no século XV, ainda no reinado de D. João I, cuja jurisdição, no Brasil, - Alvará de 10 de maio daquele ano extinguiu, ao transformar em Casa de Suplicação do Brasil a Relação do Rio de Janeiro, à qual passaram a se subordinar as demais Relações que subsistiram.

No Alvará que a instituiu, dizia o Príncipe Regente: "tomando em consideração o muito que interessa o estado e o bem comum e particular dos meus leaes vassallos em que a Administração da Justiça não tenha embaraços que a retardem e estorvam e se faça com a promptidão e exactidão que convém, e que afiança a segurança pessoal e dos sagrados direitos de propriedade que muito desejo manter como a mais segura base da sociedade civil; e exigindo as actuaes circumnstancias novas providências, não só por estar interrompida a communicação com Portugal e ser por isto impraticável seguirem-se os aggravos ordinários e appelações que até aqui se interpunham para a Casa de Supplicação de Lisboa, vindo a ficar os pleitos sem decisão última, com manifesto detrimento dos litigantes e do público que muito interessam em que não haja incerteza de domínios e se findem os pleitos quanto antes; como também por me achar residindo nesta Cidade que deve por isso ser considerada a minha Côrte actual; 
querendo providenciar de um modo seguro estes inconvenientes $\mathrm{e}$ os que podem recrescer para $o$ futuro em benefício do augmento e prosperidade da causa pública; sou servido determinar o seguinte: I - A Relação desta Cidade se denominará Casa da Supplicação do Brazil e será considerada como Superior Tribunal de Justiça, para se findarem alli todos os pleitos em última instancia, por maior que seja o seu valor, sem que das últimas sentenças proferidas em qualquer das Mesas da sobredita Casa se possa interpor outro recurso que não seja o das revistas nos termos restrictos do que se acha disposto nas minhas Ordenações, Leis e mais disposições. E terão os Ministros a mesma alçada que têm os da Casa de Supplicação de Lisboa.

II - Todos os aggravos ordinários e appelações do Pará, Maranhão, Ilhas dos Açores e Madeira, e da Relação da Bahia que se conservará no estado em que se acha, e se considerará como immediata à desta Cidade, os quaes se interpunham para a Casa da Supplicação de Lisboa, serão daqui em diante interpostos para a do Brazil e nella se decidirão finalmente pela mesma forma que o erão até agora, segundo as determinações das minhas Ordenações e mais disposições régias.

III - Todos aquelles pleitos em que houve interposição de aggravos; ou appellações que se não remetteram; e todos os que sendo remettidos, não tiveram ainda final decisão, serão julgados na Casa da Supplicação do Brazil, uns pelos próprios autos e outros pelos traslados que ficaram, pela maneira, com que o seriam na de Lisboa, por Juízes da Casa que o não foram nas primeiras sentenças. $E$ os embargos que na execução se tiverem mandado remetter, se decidirão pelos mesmos Juízes que ordenaram a remessa, sem attenção ao despacho que a decretara, a fim de fazerem final decisão, como cumpre ao bem público."

Essa, a Casa da Suplicação do Brasil - que pela sua importância, como salienta CÂNDIDO MENDES, "era superior a todas as Relações da Monarchia Portugueza" - foi que veio a se finar, vinte anos depois, quando a lei de 18 de setembro de 1828, cumprindo o que determinara a Constituição Imperial 
de 25 de março de 1824, instituiu, em nosso país, o Supremo Tribunal de Justiça. Em verdade, em seu artigo 163, essa Constituição impuzera que na Capital do Império existisse, além da Relação, Supremo Tribunal de Justiça a que se entregasse a competência de: "I - Conceder, ou denegar Revistas nas Causas, e pela maneira, que a Lei determinar. II - Conhecer dos delictos, e erros de Officio, que commetterem os seus Ministros, os das Relações, os Empregados no Corpo Diplomatico, e os Presidentes das Provincias. III - Conhecer, e decidir sobre os conflictos de Jurisdicção, e competência das Relações Provinciaes". Esse o remate que teve o projeto de Bernardo Pereira DE VASCONCELOS, oferecido em sessão da Câmara de 7 de agosto de 1826.

Com a República, dessa estrutura sairia o Supremo Tribunal Federal que, com os predicados de órgão máximo do Poder Judiciário, como expressão da soberania nacional, se desvincularia de subordinações, para o velamento da Constituição e do sistema jurídico federal. Já em 20 de fevereiro de 1890, tendo em conta "os princípios garantidores da independência do poder judicial que devem ser afirmados e escrupulosamente observados", atribui-se ao Supremo Tribunal de Justiça a prerrogativa - que antes não tinha - de eleger o seu Presidente, conferindo igual competência às Relações.

Embora a primeira referência ao Supremo Tribunal Federal estivesse no Decreto 510, de 22 de junho de 1890, que, em seu preâmbulo, convocara a reunião do Congresso Nacional para 15 de novembro de 1890, o certo é que o Governo Provisório - sob a inspiração do Ministro da Justiça - baixou, a 11 de outubro daquele ano, o Decreto 848 que regulava a estrutura daquele Tribunal e em cuja Exposição de Motivos acentuava CAMPos SALLES:

"O principal, sinão o unico intuito do Congresso na sua primeira reunião, consiste sem dúvida em collocar o poder público dentro da legalidade. Mas esta missão ficaria certamente incompleta si, adotando a Constituição e elegendo os depositários do poder executivo, não estivesse todavia previamente organizada a Justiça Federal, pois que só assim poderão ficar a um tempo e em definitivo constituidos os tres principaes orgãos da soberania nacional. Trata-se, portanto, com este acto, de adoptar o processo mais rapido para a execução do programma do Governo Provisorio no seu ponto culmi- 
nante - a terminação do período dictatorial. Mas o que principalmente deve caracterizar a necessidade da immediata organização da Justiça Federal é o papel da alta preponderência que ella se destina a representar, como órgão de um poder, no corpo social. Não se trata de tribunaes ordinarios de justiça, com uma jurisdição pura e simplesmente restricta à applicação das leis nas múltiplas relações do direito privado. A magistratura que agora se instala no paiz, graças ao regimen republicano, não é um instrumento cego ou mero intérprete na execução dos actos do poder legislativo. Antes de applicar a lei cabe-lhe o direito de exame, podendo dar-lhe ou recusar-lhe sancção, si ella lhe parecer conforme ou contrária à lei organica."

Mais adiante, ainda acrescentava:

"A funcção do liberalismo no passado, diz um eminente pensador inglez, foi oppor um limite ao poder violento dos reis : o dever do liberalismo na epoca actual é oppor um limite ao poder ilimitado dos parlamentos. Essa missão historica incumbe, sem duvida, ao poder judiciario, tal como o architectam poucos povos contemporaneos e se acha consagrado no presente decreto. Ahi está posta a profunda diversidade de indole que existe entre o poder judiciario, tal como se achava instituido no regimen decahido, e aquelle que agora se inaugura, calcado sobre os moldes democraticos do systema federal. De poder subordinado, qual era, transforma-se em poder soberano, apto na elevada esphera da sua autoridade para interpor a benefica influencia do seu criterio decisivo afim de manter o equilibrio, a regularidade e a propria independencia dos outros poderes, assegurando ao mesmo tempo o livre exercicio dos direitos do cidadão."

Depois, advertia:

"Tanto quanto e possivel e dentro dos limites naturalmente postos à previsão legislativa, ficou garantida a soberania do cidadão. É este certamente $\mathbf{o}$ ponto para onde deve convergir a mais assidua de todas as preoccupações do governo republicano. $O$ ponto de partida para um solido regimen de liberdade está na garantia dos direitos individuaes. 
O princípio fundamental de que só um poder judicial independente é capaz de defender com efficacia a liberdade e os direitos dos cidadãos na lucta desigual entre o individuo e o Estado, foi neste organismo rigorosamente observado."

A linha de pensamento dessa Exposição de Motivos orientou-se, fundamentalmente, a Constituição Republicana de 24 de fevereiro de 1891, à luz do disposto em seus artigos 55 a 59, este fulcro da competência atribuída ao Supremo Tribunal Federal, incluindo-se entre as suas prerrogativas a função de assegurar a inteireza objetiva do direito federal.

Importante assinalar-se, ademais, que na recomendação feita a SALVADOR DE MENDONÇA e LAFAYETTE RODRIGUES Pereira, que iam aos Estados Unidos em missão oficial, em julho de 1889, o Imperador já incluia o estudo da Organização da Suprema Corte Americana, em cujas funções acreditava estar o segredo do bom funcionamento da Constituição daquele país, acrescentando, com a consciência do que aqui vinha ocorrendo: "Quando voltarem, haveremos de ter uma conferência a este respeito. Entre nós as coisas não vão bem, e parece-me que se propuséssemos criar aqui um tribunal igual ao norte-americano, e transferir para ele as atribuições do Poder Moderador da nossa Constituição, ficaria esta melhor".

Como já tivemos ocasião de acentuar, "grandes momentos foram e continuam a ser vividos pelo Supremo Tribunal Federal, no cumprimento de suas nobres atribuições; nomes da maior eminência fizeram e fazem a sua estrutura fundamental. Em seu próprio cotidiano há, sempre, a beleza de sua missão, expressa numa dialética que se pode reduzir a monossílabos - ora um sim, ora um não, como expressões últimas da palavra derradeira que a ele cabe proferir.

Se o dado essencial ao conceito de nação está na possibilidade de relações, nas particularidades que marcam os episódios da vida está o sentido da sua própria realidade, no que ela tenha de coerente ou incoerente - fonte de estudo do comportamento dos povos e da natureza humana, vinculada aos limites naturais de tempo e espaço. Joga-se, aí, com o passado, com as experiências coerente ou incoerentemente vividas que fazem as tradições, com as inclinações que o presente acentue, indicando o que virá, num futuro breve ou remoto. Um fundo de psiquismo dominante interfere no lastro dessas tradições. Circunstâncias e humor, fatos e sensibilidade, realizam o destino dos povos, na medida dos valores que façam prevalecer." 
Nesse quadro, avulta o perfil das instituições que vão estabelecendo o clima próprio da convivência social, à medida que se definem os momentos históricos e se afinam as características dos povos. Há, mesmo, um condicionamento recíproco entre os impulsos que qualificam a atitude dos homens, em face da realidade que os cerca, e as instituições que nada mais são do que o reflexo das posições que as comunidades vão tomando, em face da vida e de suas imposições. Porque há, em tudo isso, determinantes espirituais e materiais que explicam essas imposições, toda uma gama de valores se equaciona, traduzindo-se em concepções que tendem a ressalvá-las, na medida em que correspondam, no tempo e no espaço, às exigências do bem comum. A história da humanidade revela esse processo em que a visão momentânea, certa ou equívoca, determina os lances de tranqüilidade ou intranqüilidade, compondo, em sua sucessão, o desenrolar cíclico dos acontecimentos, sempre afinados aos nossos acertos ou desacertos, não raro difíceis de ponderar pelo abandono - consciente ou inconsciente, pouco importa - de paradigmas aptos a orientar as nossas opções, nos momentos decisivos de que participamos. Mas há, sempre, valores primordiais que importa preservar, porque próprios da natureza humana e, pois, essenciais à nossa existência. Em torno deles gravitam os problemas de índole social que assinalam os períodos de choque, e na sua ressalva devem assentar as soluções que preservem a linha fundamental da evolução que temos de cumprir.

A Noção de Justiça talvez seja a mais profunda tomada de consciência, em face desses problemas, com que o homem se defronta, permanentemente, des,de que se apercebeu do mundo, em seu derredor, e dos outros homens, estes pela apuração das dissemelhanças que, paradoxalmente, lhes determinam igualdade de origem e predestinação - dois marcos, também paradoxais, do finito no infinito.

A visão horizontal que então teve, ainda hoje permanece, não obstante as reduções científicas que nos permitiram a conquista do espaço. Apenas os horizontes se ampliaram, acentuando, ainda mais, as nossas limitações.

Então e agora, o sentido da Justiça assimila o caminhamento da adaptação social, apontado pelo Direito, numa linha evolutiva em que concepções fundamentais permanecem, variando os engastes acidentais que, em épocas de crise, assumem feição de essenciais, provocando os chamados retrocessos que comprometem a fluência natural dos fatos, até que se reenca- 
deiem, por imposição daqueles valores que definem o homem, na sua verdadeira dimensão espiritual.

"O hoje - acentuamos, alhures — é, apenas, a afirmação do ontem e a perspectiva do amanhã, como pontos de referência num espaço sem contornos. O aqui, numa alusão ao lá, ou ao acolá, própria de quem quer situar-se numa dimensão definível. O agora, neste lugar, uma tentativa de reter o indimensionável no dimensionável, tão própria da natureza humana. Em tudo, a relação sujeito-objeto que exprime a capacidade perceptiva de cada um de nós e condiciona a nossa postura, em face da vida.

Este momento é nosso, aqui e agora, porque nele figuramos. Inexiste para os que, aqui e agora, não estão. Tem sentido e significado, como realidade sensível, para nós que aqui estamos. Existe, embora não sensibilize os que estão alhures, em outro aqui e agora, para nós inexistente. Este momento é, pois, nosso, como nossos foram os momentos que o prepararam, ao longo do tempo, em que também figuramos. Pedaços de sensibilidade que se entrelaçam e marcam o nosso itinerário comum. Nele estão os signos do bem e do mal, do maravilhoso e do repugnante, do labor e do ócio, da alegria e da tristeza, do amor e do ódio, da fé e da descrença, da esperança e do desespero, da caridade e do egoismo. Assim somos, todos nós, nos contrastes que nos podem levar, ora ao desalento, ora à realização dos mais belos sonhos!

Às conseqüências desses fluxos e refluxos não são imunes as instituições que têm, também, a par de seu cotidiano de rotinas, os seus momentos maiores.

Entre os grandes momentos do Supremo Tribunal que dão a medida da sua grandeza, está a sessão solene que, em 3 de novembro de 1949, realizou, em homenagem a RUI BARBOSA que, ao ver denegado, contra o voto de Piza e Almeida, Habeas Corpus impetrado, em 1892, não hesitara em criticar os votos vencedores, sob a ressalva da elevação com que o fazia, dizendo: "Ninguém descubra nas minhas palavras ofensa ou desrespeito ao Supremo Tribunal Federal. Quizera eu aureolá-lo. Mas toda minha veneração pela sua autoridade não chega a me deslumbrar a razão, a me secar a nascente íntima das impressões do dever. Creio na honra dessa magistratura, no desinteresse pessoal dos seus membros. Mas não posso deixar de reivindicar, para os meus clientes, o direito ordinário sob as piores tiranias, de qualificar de injusta a sentença que os feriu, desde que considero evidentemente justa a causa que eles representam". 
Era a quem assim falara que a homenagem se realizava, e, ainda na sessão de 18 de setembro último, o Presidente THOMPSON FLORES - exatamente na comemoração do centésimo qüinquagésimo aniversário do Supremo - assim aludia à circunstância:

"Em homenagem que, com justiça, lhe prestou o Supremo Tribunal Federal, em 3 de setembro de 1949, assim encerrava Dario de Almeida Magalhães sua formosa e erudita oração:

'Homenageando ao maior dos advogados brasileiros, respeitáveis senhores ministros, homenageais, antes de tudo, ao advogado do Supremo Tribunal Federal, ao advogado da augusta instituição a que servís; ao reivindicador da vossa supremacia; ao patrono intemerato e intimorato da nossa judicatura, cuja majestade ele elevava a tal excelsitude que não encontrou no seu verbo iluminado expressões que a significassem, e houve de buscar nos lances da tragédia grega as palavras que vos repetiu, com ênfase apostolar:

"Eu instituo este tribunal venerando, severo, incorruptível, guarda vigilante desta terra através do sono de todos, e o anuncio aos cidadãos, para que assim seja de hoje pelo futuro adiante."

Ocupa hoje o grande brasileiro, o eminente defensor das liberdades, lugar proeminente nesta Casa. Em seu átrio, junto ao símbolo da Justiça, talhado em bronze, se encontra o busto do eminente jurista, e suas palavras proferidas perante esta Corte se insculpem no mármore para que, perenemente, continuem a transmitir a todas as gerações a mensagem impregnada da fé que nunca o fez esmorecer, na áspera caminhada, em busca de uma melhor Justiça."

Ainda recentemente, em depoimento sobre a Corte que tanto soube dignificar, dizia aquele exemplo de cidadão e magistrado que foi o saudoso ministro LUIZ GALLOTTI, aludindo a um fato que a engrandece, moralmente, ocorrido no começo da década de 1950: "um Tribunal de Justiça, apoiado em interpretação razoável da lei, considerou majorados os vencimentos de seus membros. Enviada cópia da deliberação ao 
Presidente do Supremo Tribunal, ele convenceu-se do acerto do decidido e ordenou que o aumento se estendesse aos Ministros. $\mathrm{Na}$ véspera do pagamento, à tarde, o Presidente José Linhares deu-me cópia da fundamentação, para que eu a lesse. Chegando em casa, fiz a leitura e convenci-me de que a exegese adotada não era a melhor. À noite do mesmo dia, telefonei ao Ministro Orosimbo Nonato e fui à sua casa. Ele ouviu as minhas objeções sem acolhê-las, até que uma o convenceu plenamente. Eu lhe pedi, então, que, sendo ele o Juiz de maior autoridade no Tribunal, falasse ao nosso Presidente. Respondeu-me pedindo que eu o fizesse, autorizando-me a dizer que sua opinião coincidia com a minha. Não querendo perturbar o sono do nosso Presidente, só o procurei na manhã seguinte. Expus o problema e pedi-lhe que reunisse o Tribunal. Perguntou-me então se eu concordaria em receber o aumento, caso a maioria o aprovasse. Respondi que sim, pois, num Tribunal, o voto da maioria há de prevalecer. Feita a reunião, somente dois Ministros divergiram do meu entendimento, um quanto ao mérito e outro apenas por achar tarde, uma vez que as apostilas já haviam sido feitas e o pagamento seria realizado no dia seguinte (naquele tempo, os vencimentos não eram, como hoje, depositados em Banco e, sim, efetuados por pagador, na sede do Tribunal). Ponderei, então: Se não é tardia a restituição do que a Polícia ou a Justiça poderá reclamar por ter sido recebido indevidamente, como será tardia a recusa de receber o indevido? E assim foi decidido."

Da independência de seus juízes diz bem a postura nítida do ministro XAVIER DE ALBUQUERQUE quando - em lance conhecido de todos nós - deixava bem claro: "O Poder Judiciário de que o Supremo Tribunal é a mais alta, mas não a única expressão, é absolutamente incoercível, desempenhando a sua missão constitucional com irrepreensível dignidade e altivez". E quanto às garantias da magistratura - de que ainda não dispunham os juízes ingleses, ao tempo dos Stuart, nomeados que eram sob a cláusula quandiu se bene qesserint declarou tê-las, com toda propriedade, como conquista do Estado, não dos juízes, acrescentando: "como cidadão e, se eu o fosse, como pensador político, estimaria que se restabelecessem quanto antes, em toda a sua plenitude, porque isso restituiria ao Estado brasileiro o timbre do aperfeiçoamento que lhe deve ser, enquanto Estado, consubstancial. Como juiz, porém, pouco se me dá tê-las ou não tê-las, porque tê-las, ou não tê-las, não interfere, em nada, com a dignidade que imprimo ao desempenho da minha função judicante". E estendendo a 
ressalva nobilitante à magistratura brasileira, acrescentou: "Nem por medo, nem por interesse, é servil o Poder Judiciário que cumpre, serena e dignamente, o seu dever".

Por essa altivez e pelo que significa, na estrutura fundamental do Supremo que está na qualidade de seus juízes, orgulha-nos, sobremodo, que entre os de nossa Congregação, escolhidos para compô-lo, estejam homens cuja estatura a simples enunciação de seus nomes revela: PEDRo AUGUSTo CARNEIRo Lessa, JoÃo MENDES DE ALMEIDA JÚNIOR, UladislaU Herculano de Freitas, CÂndido MotTa Filho, Moacyr Amaral Santos e José Carlos Moreira Alves - que, nesta solenidade, nos dá a honra e a alegria de sua presença.

Dentre os que não participaram deste Cabido, mas, com as mesmas galas, honraram a magistratura de São Paulo na mais alta Corte de Justiça de nosso País, permitam-me mencionar, com igual reverência, os nomes consagrados de FrANCISCo Cardoso de Souza Ribeiro, Firmino Antonio DA Silva Whitaker, Laudo Ferreira de Camargo, Manuel da Costa Manso, Mário Guimarães, Pedro Rodovalho Marcondes Chaves, Rafael de Barros Monteiro e José Geraldo RodriGUES DE ALCKMIN, todos antigos alunos desta Faculdade.

Após o lutuoso e inesperado falecimento de ALCKMIN, quem marca - com os atavios da sua inteligência e do seu saber - a presença de São Paulo e desta Congregação no Supremo Tribunal Federal, é o nosso eminente Catedrático de Direito Civil, Professor José Carlos Moreira Alves. Sobre os onze magistrados que o integram pesa, hoje, multiplicada responsabilidade. Primeiro, em face da competência que lhes é atribuída pela Constituição da República, abrangente da originária, da recursal ordinária e da recursal extraordinária, a que, já agora, se acrescentam atribuições de acentuado relevo, seja para a disciplina procedimental que lhes foi delegada, seja para a curiosa problemática do chamado incidente de relevância, seja para as avocações.

Como se isso não bastasse, exatamente nestes dias, quando - Legislativo ultima a votação da Lei Orgânica da Magistratura, com ela mais se avolumarão as responsabilidades do Supremo, porque mais amplas e mais fundas serão as suas atribuições, especialmente no plano de um poder correcional até agora, curialmente, reservado aos Tribunais estaduais, nos limites de sua jurisdição. Adstrito a exercê-lo, saberá o Supremo medi-lo, com redobrada prudência, para ressalva da dignidade 
da magistratura brasileira que se quer intemerata e serena no exato e escorreito cumprimento de sua missão.

Não é este o momento de pormenorizar todos esses temas, despiciendas que são tais minúcias, quando se cura de assinalar o apreço desta Faculdade pelo órgão supremo do Poder Judiciário em nosso País. Antes, é hora de acentuarmos que as evidências de hoje - exatamente pelas circunstâncias que envolveram o transcurso memorável do dezoito de setembro deste ano de mil novecentos e setenta e oito - superam a realidade de ontem que a notícia carinhosa de AlIOMAR BALEEIRo pôs em relevo. A notoriedade augusta que merece o Supremo Tribunal Federal - como guarda das nossas melhores tradições de Justiça, Civismo e Liberdade - teve-a ele, como alvo de manifestações as mais expressivas, em todo o território nacional, pelo completamento dos cento e cinqüenta anos de sua instituição.

Quando se qualifica a Justiça de distributiva - tivemos ensejo de observar, nesta mesma Casa - “já se está a predeterminar a liberdade, segundo a sua dimensão, no plano da maior igualdade de cada um, para alcançar-se melhor homogeneidade social. A preocupação do estadista há de voltar-se para a segurança das liberdades do cidadão consciente de seus direitos e deveres em face da comunidade a que pertença e para a disciplina da maior igualdade, na medida em que seja possível e viável estabelecê-la, sem comprometimento da liberdade fundamental que constitui o substrato mesmo da dignidade humana. A democracia é meio que há de tender, instrumentalmente, a esses fins, pena de desvirtuar-se, no que tem de essencial.

Tudo isso explica porque os povos contemporâneos se vêem perplexos ante o problema da interdependência dos fatos sociais que está acima dos indivíduos. Na coordenação deles está a teleologia das novas estruturas jurídicas que o mundo está a reclamar, a que cada um de nós deve dar a contribuição que puder, para que se faça possível a solução do problema, em termos de eliminação de contrastes e assimilação social de seus efeitos.

Nessa tarefa avulta o perfil do Supremo Tribunal Federal, pela sua função de resguardar a inteireza objetiva do direito federal e de assegurar os direitos subjetivos e as garantias individuais, segundo as exigências da adaptação social, impostas pelo bem comum. Oportuna, pois, a advertência do salmista com que seu Presidente, Ministro ThOMPson FloREs, rematou 
seu discurso de 18 de setembro último, traduzindo, numa atitude de humildade, a melhor das esperanças:
"Se o Senhor não guardar a cidade, debalde vigiam as sentinelas."

O Senhor guardará a cidade; as sentinelas não vigiarão inutilmente. Aquele o signo; este o presságio.

Para que se tenha certeza do agouro, retomemos os fatos e as circunstâncias dos fatos que a ele nos levam.

Com a proclamação da República cuidava-se de harmonizar os regionalismos naturais - próprios do nosso módulo continental que a deficiência dos meios de comunicação acentuava - de que nasciam tendências conflitantes entre as lideranças estaduais, acirradas pela sedução do poder central. Neles já interferia - como elemento de coordenações e disjunções das correntes do pensamento nacional em formação - o dado econômico, quando se colocava o problema do "controle" do poder político, dominado pelo liberalismo que fizera ruir, na Europa, velhas estruturas e assentava, na América, as bases de novas concepções de governo. No fundo, conflitos que, no período colonial, o estilo de exploração das nossas riquezas provocara e que a República iria enfrentar, com as seqüelas do entretempo monárquico, no esquema fundamental de liberdade que a vira nascer.

Colocado no vórtice desses conflitos que repercutiam no plano dos interesses públicos e no âmbito dos interesses privados, o Supremo Tribunal Federal, órgão maior de um poder que não legisla nem administra, iria ser o elemento de disciplina dos interesses em jogo, mediante critérios de pacificação social que uma atuação, não raro pretoriana, acabaria por impor, provocando reformulações de conceitos, a final admitidos pelo legislador, como expressão da consciência jurídica nacional que assim se foi formando.

Nos últimos tempos, embora tenham se alterado os dados fundamentais da equação econômica, problemática idêntica subsiste, impondo novas soluções que o Direito, como um dos mais relevantes processos de adaptação social, deve prover, especialmente para evitar desvios no encadeamento da ordem jurídica às imposições coerentes do fio histórico. A vigilância do Supremo Tribunal Federal continua sendo, pois, da maior importância, mormente quando se sabe que o Poder Judiciário lida com regras escritas, para tratá-las segundo principios superiores, decorrentes da realidade dos fatos sociais que os 
tempos modernos, ecumenicamente, vem revelando, a fim de chegar às soluções exatas, segundo o direito.

O velamento a que se entregam os seus juízes há de conduzi-los à moderação que o Direito impõe porque - rentes aos ensinamentos do Saltério - não se deixam levar pelo conselho dos ímpios, nem enveredam pelo caminho dos pecadores, nem tomam assento na companhia dos soberbos, mas se comprazem na lei do Senhor e a meditam, dia e noite. São como a árvore plantada à beira das águas correntes que, em tempo próprio, dá o seu fruto, e cujas folhas não murcham.

\section{Senhores}

Quando se reúne a Congregação de Mestres da Faculdade de Direito da Universidade de São Paulo - aquela

"velha e sempre nova Academia" da

"bela mocidade a florescer"

- para comemorar a passagem de século e meio da existência augusta do Supremo Tribunal Federal, o que aqui se realiza e consuma é um ato de fé, dominado pelo rumor antigo de passos que trilham, juntos, há cento e cinqüenta anos, o mesmo caminho, num itinerário que leve à afirmação deste país, no sentido dos ideais de Liberdade que animam a nossa gente no vigor cívico e no amor ao Direito. É, também, uma afirmação das nossas melhores esperanças, firmes na crença dos que realmente crêem no que fazem, certos de que o fazem para o futuro maior deste país, sem nenhuma vacilação, porque se habituaram na marinhagem e sabem que, nos mares tempestuosos na expressão poética da Ode Marítima - é preciso

"Ter a audácia ao vento dos panos das velas!

Ser, como as gaveas altas, o assobio dos ventos!" Arcadas, 4 de dezembro de 1978. 